\title{
Pricing knowledge and funding research of new technology sectors in a growth model
}

\author{
Etienne Chantrel* \\ Toulouse School of Economics (GREMAQ) and PSE \\ André Grimaud ${ }^{\dagger}$ \\ Toulouse School of Economics (IDEI and LERNA ) \\ and Toulouse Business School \\ Frederic Tournemaine \\ School of Economics and University of Chicago-UTCC Research Center \\ University of the Thai Chamber of Commerce
}

\begin{abstract}
A radical evolution of intellectual property law and practices has followed the rise in importance of new technology industries. Many patents today directly protect knowledge. We endeavour to account for this evolution in a simple R\&D-based growth model. To deal with the non-convexity property of technologies in which knowledge is an input and fund research privately, we construct a dynamic general equilibrium with Cournot competition and free entry where knowledge is exchanged on competitive micro-markets that can be subject to imperfect exclusion.
\end{abstract}

JEL Classification: O31, O34.

Keywords: intellectual property rights; knowledge; new technology; non-convexity.

*Address: GREMAQ, Toulouse School of Economics, 21 allée de Brienne 31000 Toulouse France; e-mail: etienne.chantrel@normalesup.org

${ }^{\dagger}$ Address: Toulouse School of Economics (IDEI and LERNA ) and Toulouse Business School , 21 allée de Brienne 31000 Toulouse France; e-mail: grimaud@cict.fr

$¥$ Address: 126/1 Vibhavadee-Rangsit Road, Dindaeng, Bangkok, 10400, Thailand; e-mail: frederic.tournemaine@uc-utcc.org 


\section{Introduction}

A basic principle of intellectual property law is that an idea (a piece of knowledge) cannot be patented. Patents are limited to private goods. For example, a scientific report on the principles used in the production of a new machine cannot be patented. The patent protects only the template for the new machine. This principle, however, seems to be challenged in many sectors such as the biotechnology and software industries. Nowadays, databases, software, business plans, labeled as 'knowledge-products' by Quah $(1997,2001)$ or 'information goods' by Scotchmer (2005) because their properties are akin to those of knowledge (see below), are routinely protected by patents.

Section 2 describes this recent evolution in detail, but we can already give some examples where knowledge is directly traded and even protected by a patent. One is the chemical industry. Innovations in this industry are mostly process innovations that get largely licensed between firms (see for instance Arora and Fosfuri, 2000). The software industry provides many other examples. For instance, IBM chose in the early eighties to specialize on hardware development, licensing the characteristics of their PC platform. More recently, software patents have started to be routinely granted. In 2002, it was estimated that the United States Patent Office (USPTO) had granted more than 100,000 patents, and the European Patent Office (EPO) 30,000. In the biotechnology sector, Scotchmer (1999) mentions Incyte, Human Genome Science and Celera, companies which sell access to their data-bases at millions of dollars per year per user. We can further mention that Human Genome Science owns a patent on the gene that produces the protein CCR5. Because of the existence of this patent, the researchers of the National Institutes of Health had to buy a license to use the protein CCR5 as it enters in the production process of a medicine for AIDS. Finally, in 1992, Agracetus, later bought by Monsanto, was awarded a patent on a genetically modified cotton. The patent was later extended to include all genetically modified cotton.

The notion that knowledge can be directly patented and exchanged on markets has been developed and formalized for years by various authors such as Arrow (1962), Scotchmer (1991, 1999), Dasgupta et alii (1997), Gallini and Scotchmer (2003). However, this notion did not find its way in endogenous growth literature (e.g. Romer, 1990; Grossman and Helpman, 1991a; Aghion and Howitt, 1992). Standard growth models consider in effect that ideas are freely available and cannot be protected by intellectual property because only private goods embedding an idea can be. Although this is consistent with the principles of intellectual property law mentioned above, it seems an inadequate formalization in the case of new technologies. We can also argue that standard growth models do 
not account for the particular characteristics of the goods produced in the new technology sectors. In the case of software, for example, pieces of knowledge are embedded in private goods such as a CD-ROM or a DVD. On the face of it, this looks congruent with the usual presentation used in growth models. However, that "private" good has an almost nonexistent marginal cost of production. Therefore, it is akin to a public good and almost consubstantial with the piece of knowledge itself. In other words, there is no intermediate sector of private goods with a significant marginal cost of production.

In this context, the purpose of this paper is to develop a simple theoretical framework that accounts for the recent evolution in intellectual property law. To get there, we consider a simple growth model in which pieces of knowledge are directly protected by patents. Formally, in this paper pieces of knowledge represent databases, software algorithms or business plans. It can be discussed whether ideas will ever become patentable by default. However, in several cases, ideas that are directly used are patented (business models), and in others, there is no intermediate sector of private goods with a significant marginal cost of production (software). It is therefore interesting to state the problem as if the idea itself were patented directly. In any case, Scotchmer (2005) explains that, in the case of information goods, the template is the information itself. That is, in the new technology sectors at least, intellectual property rights directly protect knowledge. Even if we don't go as far as making the generalization that every idea is patentable, we use in our formalization the following hypothesis for new technology sectors. That is, we make the clear-cut assumption that the piece of knowledge and its storage device are fully consubstantial and state the problem as if the piece of knowledge itself were patented directly.

The primary challenge arising from this scenario is to specify the manner in which the research is funded. We cannot in effect consider the standard equilibrium in which a monopoly is granted to the firm producing the good embedding the new piece of knowledge. Moreover, the public good property of knowledge (i.e. the non rival or non-depletable good property according to the textbook definition, for instance that of Mas-Colell, Whinston and Green, 1995, ch. 11 or Scotchmer, 2005, ch. 2) ${ }^{1}$, raises two kinds of well-known problems. First, standard problems of public economics arise such as how to verify which agents use a piece of knowledge (verification problem) and how to exclude agents that do not pay to use a piece of knowledge (exclusion problem). Then, the second kind of problem we face is linked to the non convexity of technologies in which knowledge is an input. Basically, the replication argument states that technologies display constant returns to scale with respect to private inputs and increasing returns to scale

\footnotetext{
${ }^{1}$ Endogenous growth theory usually defines a public good as both non-rival and non-excludable.
} 
with respect to private and public factors taken jointly. In a competitive market, the payment of private factors fully exhausts revenue and firms are thus unable to pay for the public good they use (see e.g. Kaizuka, 1965; Sandmo, 1972; Manning et alii, 1985; Feehan, 1989; Romer, 1990; Jones, 2003). Given this fundamental problem of existence, we choose to construct a dynamic general equilibrium with Cournot competition and free entry. Thereby, imperfect competition on private goods markets allows firms to get funds to buy knowledge and research is privately funded.

Regarding the pieces of knowledge, we follow the standard literature in making the simplifying assumption that they are perfect substitutes. However, our formalization departs from the basic growth frameworks in that we consider the existence of a formal market for knowledge. We assume that pieces of knowledge are exchanged on micromarkets which work as standard competitive ones, except that there can be imperfect verification and/or exclusion. Note that beyond the case of new technologies which is the focus of this paper, we can also think of goods such as newspapers, books, movies and TV-programs. These kinds of goods are indeed non-rival, differentiated, in some sense, more or less substitutes and exchanged on markets that are almost perfectly competitive.

Formalizing the manner intellectual property law works in the new technology sectors has important implications. Under the assumption of perfect verification and exclusion, we show that the so-called distortion caused by the knowledge spill-over vanishes. This is because all agents (including researchers) must pay the right to use the patented pieces of knowledge (see e.g. examples cited above) and the markets of pieces of knowledge are competitive. Ceteris paribus, innovators appropriate the entire amount of the surplus they create which yields to an optimal research funding. Such desirable outcome seems, however, difficult to get in the real world. Though there exists institutions or protection systems such as encryption and copy controls in the case of softwares, innovators in the new technology sectors may have difficulties to prevent illegal uses of their inventions due to piracy for instance. We account for this feature in a simple way. We basically assume that innovators appropriate only a share of the total surplus they create which results in a reduction of research investments and to a lower level of growth in the long run. The contribution here is to provide an alternative explanation to this kind of result which finds empirical supports in the literature (see e.g. Jones and Williams, 1998). Here, insufficient research investments arise in a complete market setting and relies on the nonrival property of the pieces of knowledge, i.e. the problems of verification and exclusion. In contrast, in the standard literature, this result arises in an incomplete market perspective as pieces of knowledge are not priced. In standard settings, research is indeed indirectly funded by the monopoly profits on private goods embedding knowledge. This has two 
consequences. First, the incompleteness of markets explains the intertemporal spill-over distortion and second, monopolistic competition explains the appropriability effect which appears to be the most driving force leading to under-investments in research (see e.g. Jones and Williams, 2000).

The remainder of the paper is organized as follows. In Section 2, we discuss the recent evolution of intellectual property practice. Section 3 introduces the model. In Section 4 , we analyze the dynamic general equilibrium. Section 5 concludes.

\section{Intellectual property law and its evolutions}

Although intellectual property law still maintains the principle that ideas are not protected, its application has become more flexible in the past few years. Protection of inventions and artworks is not a natural institution. In fact, though the institution is old, it has been debated from the start, on moral as well as economic grounds. In the 18th century philosophers mostly opposed the extension of property rights to ideas. ${ }^{2}$ Who could prevent an idea from spreading ? Who would? Nothing should prevent the free circulation of ideas and the general progress of human knowledge. Nevertheless, the necessity to protect inventors and authors quickly appeared. This necessity is based both on moral grounds (every effort deserves a reward, every author should be protected, at a time where plagiarism was rampant) and on practical ones (creation will be fostered if it is profitable). Intellectual property law was devised with those two dimensions in mind. Authors and inventors are to be protected and rewarded, and this reward is also an incentive. It takes several forms, mainly copyright, patents and trademarks. The present paper deals chiefly with patents.

The principle that ideas are not protected has always been a simplification. Actually, some ideas have long been patentable. Patents can protect industrial processes, such as a car's blueprints or a new process to produce steel. Traditionally, patent offices distinguished between ideas (non patentable) and industrial processes (patentable, though they could be considered as ideas too). European jurisprudence drew the line at the

\footnotetext{
${ }^{2}$ Lawyers often quote Jefferson, in a letter from 1813: If nature has made any one thing less susceptible than all others of exclusive property, it is the action of the thinking power called an idea, which an individual may exclusively possess as long as she keeps it to herself ; but the moment it is divulged, it forces itself into the possession of every one, and the receiver cannot dispossess herself of it. Justice Douglas also states, in a Supreme Court decision from 1950: It was never the object of those laws to grant a monopoly for every trifling device, every shadow of a shade of an idea, which would naturally and spontaneously occur to any skilled mechanic or operator in the ordinary progress of manufactures(The Great Atlantic and Pacific Tea Co. vs. Supermarket Corp.).
} 
"technical" character of an idea. This distinction was considered meaningful because these processes or blueprints are not directly used in the final sector: a private good embeds the idea. The standard way that growth models consider research effectively regards patentable "ideas" as few. They are supposed never to be used by themselves but to be embedded in a private good, a simplification reflecting the way patent law used to work. However, even if the principles of the law have not changed, more ideas are considered patentable today. The standard simplification, even if it still complies with the principles of intellectual property law, is thus further from practical reality. With the rise of new technology industries and their high knowledge content, what could have been interpreted as exceptions in the past tends to become the rule. That is, intellectual property law has changed, so that the theoretical treatment (in endogenous growth literature) does not even reflect law as it exists today.

The main example of this evolution is the software industry. Software was originally deemed a non-technical idea, similar to a mathematical theorem. Its expression could be copyrighted, but software innovations could not be patented. In Europe, article 52.2 of the Munich convention explicitly states that software is not patentable. In the US, the US Patent Office was reluctant to grant any software-related patent, with the justification that mathematical truths are not patentable (it was following the 1972 decision Gottschalk vs Benson in which the Supreme Court considered that software was nothing more than a mathematical algorithm). Copyright was the only relevant protection: it is not possible to copy the expression of a software, but it is possible to copy its functions and concepts. The first sign of an evolution was the decision Diamond vs Diehr in 1981. The Supreme Court authorized a patent on an innovation (a new method to produce rubber) that made explicit use of a software component. A patent had been granted because that software had a tangible effect. ${ }^{3}$ Jurisprudence became gradually more flexible on what constituted a patentable software-related innovation. In 1998, the Federal Circuit Appeal Court decided, in the case State Street Bank $\&$ Trust Co. vs Signature Financial Group,

\footnotetext{
${ }^{3}$ The line was defined as follows: We view respondents claims as nothing more than a process for molding rubber products and not as an attempt to patent a mathematical formula. We recognize, of course, that when a claim recites a mathematical formula (or scientific principle or phenomenon of nature), an inquiry must be made into whether the claim is seeking patent protection for that formula in the abstract.(...) To hold otherwise would allow a competent draftsman to evade the recognized limitations on the type of subject matter eligible for patent protection. On the other hand, when a claim containing a mathematical formula implements or applies that formula in a structure or process which, when considered as a whole, is performing a function which the patent laws were designed to protect (e.g., transforming or reducing an article to a different state or thing), then the claim satisfies the requirements of section 101.
} 
Inc., that any software, and even a mere mathematical algorithm, could be patented, which seems the final point in this evolution.

A similar evolution took place in Japan. Europe long maintained the interdiction to patent a software. An evolution is visible, though. Since 1996, the EPO has started granting patents where the tangible industrial process is more and more remote. ${ }^{4}$ In practice, many software programs are now patented. The Munich convention was meant to be reformed in 2000 to allow this evolution, but the member-states (among which there are also some non-European Union members) chose to rely on a decision by the European Union. In 2002, the commission proposed a directive that would have allowed software patents. After a lengthy discussion in the European Parliament, software patents remain forbidden for now.

The extension of what is patentable is not limited to software. In the US, business models are now routinely patented. For example, the idea to keep information about online clients from one visit to another to facilitate their shopping is patented by Amazon. ${ }^{5}$ This patent is not only a threat. It has real effects: Barnes $\&$ Noble had to change their on-line shopping service so as not to infringe on the Amazon patent. Priceline.com should also be mentioned, with its patent on the use of reversed auctions. ${ }^{6}$ In line with these evolutions of new technology sectors, in our model, new pieces of knowledge are directly protected by patents.

\section{Model}

To formalize the ideas developed in Introduction and in Section 2, we develop a simple endogenous growth model with horizontal differentiation in the line of Grossman and Helpman (1991b, ch. 3), Smulders and Van de Klundert (1995, 1997), Peretto (1996, 1998, 1999). We augment these analyses, however, in considering a market for knowledge.

Time, denoted by $t$, is continuous and goes from zero to infinity. There are three kinds of goods. At each instant, differentiated goods, denoted by $X_{j t}$, are produced by an exogenous number of sectors denoted by $j(j=1, \ldots, N)$, each one comprising $Q_{j t}$ firms $\left(q_{j}=1, \ldots, Q_{j t}\right)$, where $Q_{j t}$ is endogenous. At every point in time, a continuum of pieces of knowledge $\left[0, A_{t}\right]$, where $A_{t}$ denotes the total stock of knowledge, is produced and expanding through R\&D activities. A piece of knowledge is an indivisible, infinitely-lived,

\footnotetext{
${ }^{4}$ For instance, patent EP0800142 on the 8th of October 1997 deals with a method to convert file names from the Windows 95 to the Windows NT format.

${ }^{5}$ One-click patent $(5,960,411,28$ th September 1999).

${ }^{6}$ Patent 5,794,207, 11th august 1998.
} 
differentiated and non-rival good. It can be a scientific report, a database, or a software algorithm. Although pieces of knowledge are differentiated goods, for simplicity we will treat them as perfect substitutes. That is, we can sum any intervals of the set $\left[0, A_{t}\right]$. Finally, at each instant, there is a fixed quantity of labor, denoted by $L$, which is owned by individuals as initial endowment.

To simplify the analysis and as we can find such behavior in the pharmaceutical, software or aeronautics industries, we assume that in each sector $j$ every firm $q_{j}$ engages simultaneously in the production of differentiated good $j$ and in research. Denoting by $X_{q_{j} t}$ the quantity of differentiated good produced by firm $q_{j}$, the total quantity of differentiated good $j$ is given by $X_{j t}=\sum_{q_{j}=1}^{Q_{j t}} X_{q_{j} t}$. Similarly, denoting by $A_{q_{j} t}$ the stock of knowledge produced by firm $q_{j}$ until date $t$, the quantity of knowledge produced in sector $j$ is $A_{j t}=\sum_{q_{j}=1}^{Q_{j t}} A_{q_{j} t}$, and the total stock of knowledge is given by $A_{t}=\sum_{j=1}^{N} \sum_{q_{j}=1}^{Q_{j t}} A_{q_{j} t}$. Technologies and preferences are described as follows.

At each instant, firm $q_{j}$ produces a quantity $X_{q_{j} t}$ of differentiated good $j$, along with

$$
X_{q_{j} t}=\gamma\left(A_{t}^{q_{j}}\right)^{\nu} L_{q_{j} t}^{X},
$$

where $\gamma>0,0<\nu<1, L_{q_{j} t}^{X}$ is the quantity of labor devoted to the production of differentiated good $q_{j}$ and $A_{t}^{q_{j}}$ is the stock of knowledge used by firm $q_{j}$, with $A_{t}^{q_{j}} \leq A_{t}$. Two comments are in order here. First, there is no reason to assume that firms use the whole stock of knowledge, $A_{t}$, a feature embodied in (1) and (2) below. We will see in Section 4 that such specification also facilitates the distinction between supply side and demand side when we analyze the market for knowledge. Second, technology (1) captures in a simple way the arguments on new technologies developed in Introduction and in Section 2. We assume in effect that the storage device is fully consubstantial with the piece of knowledge and thus we do not specify any intermediate goods sector embedding knowledge. ${ }^{7}$ It results that we cannot study the usual equilibrium in which research is funded by the monopoly profits on intermediate goods. Jones $(2002,2003)$ also develops models that do not incorporate any intermediate goods, i.e. he specifies technologies for output which are similar to (1). In his 2002 paper, he explains that such formalization "can be viewed as a precursor to the richer analysis that comes from adding markets to the model and analyzing equilibrium conditions" (pp. 223). In his 2003 paper, he constructs an equilibrium in which research is publicly funded. Although this strategy solves the problem of non-convexity discussed in Introduction, there is no specific market and thus

\footnotetext{
${ }^{7}$ For comparison, the equivalent technology of (1) used in standard growth models would be $X_{q_{j} t}=$ $\gamma\left(L_{q_{j} t}^{X}\right)^{\alpha} \int_{0}^{A_{t}^{q_{j}}}\left[z_{q_{j} t}(h)\right]^{1-\alpha} d h$, where $0<\alpha<1$ and $z_{q_{j} t}(h)$ would be the quantity of intermediate good $h$ which embeds the specific piece of knowledge $h, h \in\left[0, A_{t}^{q_{j}}\right]$.
} 
no specific price for knowledge. Therefore, characterizing an equilibrium in which there is a specific market and a specific price for knowledge in which research is privately funded as well as answering to a question raised by the author are another contribution of this paper.

The R\&D-technology of each firm $q_{j}$ is given by

$$
\stackrel{\bullet}{A_{q_{j} t}}=\delta L_{q_{j} t}^{A} A_{t}^{q_{j}}
$$

where $\delta>0$ and $L_{q_{j} t}^{A}$ is the amount of labor devoted to research in firm $q_{j}$. It is possible to argue that there is evidence of diminishing returns in $\mathrm{R} \& \mathrm{D}$ because the redundancy and overlap in research reduce the total number of pieces of knowledge produced by a researcher (see e.g. Jones, 1995). Similarly, it could be interesting to investigate a model including creative destruction effects like Jones and Williams (2000). Finally, to avoid the well-known problems of scale effects resulting from the specification of the R\&D technology (2), we could for example introduce endogenous human capital accumulation (see e.g. Arnold, 1998) or specify a model in the spirit of Howitt (1999) with both vertical and horizontal differentiation. As shown by Grimaud and Rouge (2004, 2008), Grimaud and Tournemaine $(2006,2007)$ who account for various of the above features in models close to ours, we would complicate but not alter the main insight of the paper. In that sense, the model presented here and more specifically technology (2) must be viewed as the choice of simplicity over complexity. This will allow us to focus on the key feature of the problem tackled in Section 4 (i.e. funding research privately when pieces of knowledge are directly protected by patents) and to obtain simple closed form solutions.

The economy is populated by $L$ identical individuals. Each one of them is endowed with one unit of labor that she supplies inelastically. Preferences of the representative individual are given by

$$
U=\int_{0}^{\infty} \frac{\left[\sum_{j=1}^{N}\left(c_{j t}\right)^{\varepsilon}\right]^{(1-\theta) / \varepsilon}-1}{1-\theta} e^{-\rho t} d t
$$

where $0<\varepsilon<1, c_{j t}$ is the consumption of differentiated good $j, \rho>0$ is the rate of time preference and $\theta$ is the inverse of the elasticity of substitution with $\theta>0$ and $\theta \neq 1$.

Since differentiated goods are used for consumption only, we have

$$
L c_{j t}=X_{j t} \quad \forall j=1, \ldots, N .
$$

Finally, the labor constraint writes

$$
L=L_{t}^{X}+L_{t}^{A},
$$


where $L_{t}^{X}=\sum_{j=1}^{N} \sum_{q_{j}=1}^{Q_{j t}} L_{q_{j} t}^{X}$ and $L_{t}^{A}=\sum_{j=1}^{N} \sum_{q_{j}=1}^{Q_{j t}} L_{q_{j} t}^{A}$ denote the aggregate quantities of labor employed in the production of differentiated goods and research, respectively.

\section{Dynamic general equilibrium}

\subsection{Basic assumptions and market for knowledge}

The purpose of this Section is to characterize an equilibrium in which pieces of knowledge are exchanged on a market. As explained in Introduction, this rises two kinds of problems. First, if we assume perfect competition on the markets of consumption goods, a general competitive equilibrium does not exist due to the property of constant returns to scale with respect to labor in the production of differentiated goods (1) and knowledge (2). To settle this problem of existence, we assume imperfect competition on differentiated consumption goods markets. More precisely, we assume Cournot competition with free entry on the market of each good $j$, and will denote by $p_{j t}$ the price of differentiated good $j, j=1, \ldots, N^{8}$

Second, we must formalize how pieces of knowledge are exchanged. As is standard in growth literature, we assume that once a firm produces a piece of knowledge, it is granted an infinitely-lived intellectual property right, akin to an infinite patent. The firm which owns a patent on a piece of knowledge uses it for her own production and sells licenses to others. For simplicity, we assume that pieces of knowledge are rented to the users, though a selling market would be equivalent. To deal with the difficulties arising from the non-rivalry property of knowledge (verification and exclusion problems), we assume that firms cannot arbitrate, i.e. they cannot resell, re-rent, copy or share a piece of knowledge to or with other firms. ${ }^{9}$ Thus, each firm can be considered as an independent market from the point of view of the sellers of knowledge: at each moment there are $\sum_{j=1}^{N} Q_{j t}$ micro-markets for knowledge and on each micro-market, each firm $q_{j}$ is characterized by an instantaneous marginal willingness to pay $v_{q_{j}}\left(A_{t}^{q_{j}}\right)$ (see equation (10) for the analytical expression of this function).

As explained before, the goods exchanged here (i.e. the pieces of knowledge) are non-rival and differentiated. Moreover, they enter in technologies (1) and (2) as perfect substitutes. This implies that the ranking of pieces of knowledge is irrelevant inside the

\footnotetext{
${ }^{8}$ Bertrand competition cannot be used here because in each sector $j$ there is a single homogenous good.

${ }^{9}$ In Section 4.4, we will relax the assumption of perfect verification and perfect exclusion and analyze how it modifies the equilibrium solutions.
} 
set $\left[0, A_{t}\right]$. To take into account the problem of substitutability, we assume that the sellers of knowledge have no market-power. This means that each micro-market works as a standard competitive market for an homogeneous good, and thus there is no problem of information because the willingness to pay of the buyers to use a piece of knowledge is revealed by the market mechanism.

In analyzing how the market for knowledge works, we must distinguish between the price paid by each firm for one piece of knowledge and the price perceived for this piece by the seller. As knowledge is non-rival, the price perceived is equal to the sum of the prices paid by all buyers. Formally, we denote by $v_{q_{j}}$ the price of a piece of knowledge on the micro-market $q_{j}$. Since the willingness to pay of firm $q_{j}$ is $v_{q_{j}}\left(A_{t}^{q_{j}}\right)$, the demand function is $v_{q_{j}}^{-1}\left(v_{q_{j}}\right)$. At each moment, the firm faces the total supply $A_{t}$, i.e. at each moment the total supply is inelastic. Thus, in equilibrium, the price $v_{q_{j} t}$ is solution of $v_{q_{j}}^{-1}\left(v_{q_{j}}\right)=A_{t}$, that yields $v_{q_{j}}=v_{q_{j}}\left(A_{t}\right)$ for all $q_{j}$. This means that in equilibrium the rental price of a piece of knowledge adjusts so that each firm uses effectively the total stock of knowledge: $A_{t}^{q_{j}}=A_{t}$. Since $v_{t}$ is a rental price, the value of a piece of knowledge, $V_{t}$, is given by $V_{t}=\int_{t}^{\infty} v_{s} e^{-\int_{t}^{s} r_{u} d u} d s$, where $r_{u}$ is the interest rate of the perfectly competitive financial market. Let us note that different firms generally pay different rental prices for a piece of knowledge, $v_{q_{j}}$, which is a standard practice in the biotechnology sector, pharmaceutical or software industries. However, the total price perceived by a seller, $v_{t}$, is the same for any piece because the aggregate marginal productivities of each piece of knowledge are the same. We can recapitulate the main features regarding how the knowledge market works as follows:

Proposition 1 : In equilibrium, under the assumption that pieces of knowledge are exchanged on perfectly competitive micro-markets:

a) each firm $q_{j}$ uses the whole stock of knowledge: $A_{t}^{q_{j}}=A_{t}$;

b) the price of a piece of knowledge at any moment $t$ is given by the marginal willingness to pay: $v_{q_{j} t}=v_{q_{j}}\left(A_{t}\right)$;

c) the price perceived by a firm for the renting of a piece of knowledge at any moment $t$ is given by $v_{t}=\sum_{j=1}^{N} \sum_{q_{j}=1}^{Q_{j t}} v_{q_{j}}$;

d) the value of a piece of knowledge is given by $V_{t}=\int_{t}^{\infty} v_{s} e^{-\int_{t}^{s} r_{u} d u} d s$.

Before turning to the formal characterization of the equilibrium, let us mention that we assume perfect competition on the labor market and we normalize the price of labor to one: $w_{t}=1$. Moreover, for more clarity, we shall find it convenient to give the following Definition of the equilibrium with Cournot competition and free entry in which pieces of knowledge are directly patented: 
Definition 1 : An equilibrium is a set of profiles of number of firms $\left(\left\{Q_{j t}\right\}, j=1, \ldots, N\right)$, of quantities of goods $\left(\left\{c_{j t}\right\}, j=1, \ldots, N,\left\{X_{q_{j} t}\right\},\left\{L_{q_{j} t}^{X}\right\},\left\{L_{q_{j}}^{A}\right\},\left\{A_{q_{j} t}\right\},\left\{A_{t}^{q_{j}}\right\}, q_{j}=\right.$ $\left.1, \ldots, Q_{j t}, j=1, \ldots, N\right)$, and of prices $\left(\left\{p_{j t}\right\}, j=1, \ldots, N,\left\{v_{q_{j} t}\right\}, q_{j}=1, \ldots, Q_{j t}, j=\right.$ $\left.1, \ldots, N,\left\{v_{t}\right\},\left\{V_{t}\right\},\left\{r_{t}\right\}\right)$ such that:

- the labor market and the financial market are perfectly competitive;

- on each differentiated good market, there is Cournot competition with free entry;

- each firm rents knowledge on an independent micro-market which works as a perfectly competitive one;

- the representative individual maximizes her utility and firms maximize their profits.

\subsection{Characterization of the equilibrium}

The representative individual maximizes (3) subject to the budget constraint $\dot{b}_{t}=r_{t} b_{t}+$ $w_{t}-\sum_{j=1}^{N} p_{j t} c_{j t}$, where $b_{t} \equiv A_{t} V_{t} / L$ is the per-capita stock of wealth (recall that $w_{t}$ is equal to one). The solution of this program is standard. The individual's demand function for each consumption good $j$ is $c_{j t}=E_{t}\left(p_{j t}\right)^{1 /(\varepsilon-1)}$, where $E_{t}=\sum_{k=1}^{N} p_{k t} c_{k t} / \sum_{k=1}^{N}\left(p_{k t}\right)^{\varepsilon /(\varepsilon-1)}$. Using (4), we get the inverse demand function for differentiated good $j$ :

$$
p_{j t}=\left(L E_{t}\right)^{1-\varepsilon}\left(\sum_{q_{j}=1}^{Q_{j t}} X_{q_{j} t}\right)^{\varepsilon-1} .
$$

The Keynes-Ramsey rule is:

$$
r_{t}=(1-\varepsilon) g_{c_{j t}}+\left[1-\frac{(1-\theta)}{\varepsilon}\right] g_{\Omega_{t}}+\rho+g_{p_{j t}},
$$

where $g_{\Omega_{t}}$ is the growth rate of $\sum_{j=1}^{N}\left(c_{j t}\right)^{\varepsilon}$.

Firms have two activities: 1) each one produces and sells a differentiated good on an imperfect market (competition à la Cournot); 2) simultaneously, each one produces and rents new pieces of knowledge. Each firm $q_{j}$ maximizes the sum of the present values of expected profits

$$
\pi_{q_{j} 0}=\int_{0}^{\infty}\left[p_{j t} X_{q_{j} t}-L_{q_{j} t}^{X}+v_{t} A_{q_{j} t}-L_{q_{j} t}^{A}-v_{q_{j} t} A_{t}^{q_{j}}\right] e^{-\int_{0}^{t} r_{u} d u} d t
$$

subject to $X_{q_{j} t}=\gamma\left(A_{t}^{q_{j}}\right)^{\nu} L_{q_{j} t}^{X}$ (see equation (1)), $\dot{A}_{q_{j} t}=\delta L_{q_{j} t}^{A} A_{t}^{q_{j}}$ (see equation (2)) and the inverse demand function $p_{j t}=\left(L E_{t}\right)^{1-\varepsilon}\left(\sum_{q_{j}=1}^{Q_{j t}} X_{q_{j} t}\right)^{\varepsilon-1}$ (see equation (6)). After 
substitution, the Hamiltonian of this problem is

$$
\begin{aligned}
H_{t}= & \left\{X_{q_{j} t}\left[\left(L E_{t}\right)^{1-\varepsilon}\left(\sum_{q_{j}=1}^{Q_{j t}} X_{q_{j} t}\right)^{\varepsilon-1}-\left(A_{t}^{q_{j}}\right)^{-\nu} / \gamma\right]+v_{t} A_{q_{j} t}-L_{q_{j} t}^{A}-v_{q_{j} t} A_{t}^{q_{j}}\right\} e^{-\int_{0}^{t} r_{u} d u} \\
& +\xi_{t} \delta L_{q_{j} t}^{A} A_{t}^{q_{j}}
\end{aligned}
$$

where $\xi_{t}$ is the co-state variable associated with (2). In this problem, the choice variables are $X_{q_{j} t}$ (production of differentiated good), $L_{q_{j} t}^{A}$ (quantity of labor employed in research), $A_{t}^{q_{j}}$ (quantity of knowledge to be used in the production processes) and $A_{q_{j} t}$ (the quantity of knowledge to be produced). The first order conditions are $\partial H_{t} / \partial X_{q_{j} t}=0, \partial H_{t} / \partial L_{q_{j} t}^{A}=$ $0, \partial H_{t} / \partial A_{t}^{q_{j}}=0, \partial H_{t} / \partial A_{q_{j} t}=-\dot{\xi}_{t}$, and the transversality condition stating that the value of a firm's $q_{j}$ stock of knowledge is zero at the end of the planning horizon is given by: $\lim _{t \rightarrow \infty} \xi_{t} A_{q_{j} t}=0$.

After computations described in Appendix, we get:

$$
\begin{gathered}
X_{j t}=L E_{t}\left\{\gamma\left(A_{t}^{q_{j}}\right)^{\nu}\left[1+(\varepsilon-1) \frac{X_{q_{j} t}}{X_{j t}}\right]\right\}^{1 /(1-\varepsilon)}, \\
V_{t} \delta A_{t}^{q_{j}}=1, \\
v_{q_{j} t}=\frac{\left(\nu L_{q_{j} t}^{X}+L_{q_{j} t}^{A}\right)}{A_{t}^{q_{j}}} .
\end{gathered}
$$

Equation (8) implicitly yields the best response of firm $q_{j}, X_{q_{j}}$, to the choice of production of differentiated good $j$ of the others. Equation (9) states that the value of one piece of knowledge, $V_{t}$, is equal to the marginal cost. Indeed, from (2) we get $L_{q_{j} t}^{A} / \dot{A}_{q_{j} t}=1 / \delta A_{t}^{q_{j}}$ which is the marginal cost since the wage is normalized to one. Finally, equation (10) gives the willingness to pay, $v_{q_{j}}\left(A_{t}^{q_{j}}\right)$, that we have used in Section 4.1 to analyze how the market for knowledge works. It is composed of two parts. The first one, $\nu L_{q_{j} t}^{X} / A_{t}^{q_{j}}$, can be interpreted as the willingness to pay at date $t$ to use a piece of knowledge at $t$ for the production of the differentiated good; the second one, $L_{q_{j} t}^{A} / A_{t}^{q_{j}}$, is the willingness to pay to use a piece of knowledge at date $t$ in order to make research at $t$. We thus have here an analytical representation of the public good (non-rival) nature of knowledge inside the firm: each unit of knowledge is used twice by each firm. Note that this expression has another interpretation. That is, innovators are directly rewarded by any kind of agent using their knowledge: here, producers of differentiated goods and researchers. This kind of interpretation differs from the one we have in the standard R\&D-based literature where 
researchers have a free access to the stock of knowledge. We will come back in more details on this important point in Section 4.3 where it is more appropriate. To pre-amble, this result comes from the fact that knowledge is directly patented and priced in our model, i.e. this is the outcome of the formalization of new practices of intellectual property law regarding the new technology sectors.

\subsection{Symmetric equilibrium}

In order to get simple solutions, from now on we assume that all firms are identical, i.e. we focus on a symmetric equilibrium, and we assume that the number of firms in each sector, $Q_{j t}$, is a continuous variable. A symmetric equilibrium is defined as follows:

Definition 2 : A symmetric equilibrium is characterized by a number of firms in each sector $j$, quantities and prices that are identical for all $q_{j}$ and for all $j: Q_{j t}=Q_{t}$ for all $j, X_{q_{j} t}=X_{j t} / Q_{t}=X_{t} / Q_{t}, L_{q_{j}}^{X}=L_{j t}^{X} / Q_{t}=L_{t}^{X} /\left(N Q_{t}\right), L_{q_{j} t}^{A}=L_{j t}^{A} / Q_{t}=L_{t}^{A} /\left(N Q_{t}\right)$, $A_{q_{j} t}=A_{j t} / Q_{t}=A_{t} /\left(N Q_{t}\right)$, for all $q_{j}$ and for all $j ; p_{j t}=p_{t}$ for all $j$.

As shown in Appendix, manipulation of (1)-(10) along with Proposition 1 and Definition 2 leads to Proposition 2 below which the summarizes the results we get at steadystate. For convenience, time subscripts are dropped when variables are constant, but kept for individual, perpetually growing, variables.

Proposition 2 : The steady-state symmetric dynamic general equilibrium with Cournot competition and free entry is characterized by a set of quantities, prices, growth rates and a number of firms in each sector $j, j=1, \ldots, N$, that take the following values:

Quantities:

$$
L^{A}=\frac{\delta \nu L-\rho}{\delta \nu \theta}, \quad L^{X}=\frac{\delta \nu L(\theta-1)+\rho}{\delta \nu \theta}, \quad L c_{t}=X_{t}=\frac{\gamma\left(A_{t}\right)^{\nu} L^{X}}{N}, \quad A_{t}=A_{0} \exp \left\{g_{A} t\right\}
$$

Prices:

$$
p_{t}=\left(\frac{L}{L^{X}}\right)\left(\frac{1}{\gamma\left(A_{t}\right)^{\nu}}\right), \quad v_{t}=\frac{\left(\nu L^{X}+L^{A}\right)}{A_{t}}, \quad V_{t}=\frac{1}{\delta A_{t}}, \quad r=\frac{\delta \nu L(\theta-1)+\rho}{\theta}
$$

Growth rates of quantities:

$$
g_{L^{A}}=g_{L^{X}}=0, \quad g_{c}=g_{X}=\frac{\delta \nu L-\rho}{\theta}, \quad g_{A}=\frac{\delta \nu L-\rho}{\nu \theta} .
$$

Growth rates of prices:

$$
g_{p}=-\nu g_{A}, \quad g_{v}=g_{V}=-g_{A}, \quad g_{r}=0 .
$$


Number of firms in each sector:

$$
Q=\frac{\nu \delta \theta L(1-\varepsilon)}{\nu \delta L-\rho}
$$

\section{Proof. : See Appendix.}

Comments are in order here. Although the number of firms is endogenous, there are no transitional dynamics in the symmetric equilibrium. The reason is that there is no fixed or sunk cost of entry and exit for the firms (see e.g. Peretto, 1996). Thus, the number of firms in each sector, $Q$, is a jump variable. Existence of such steady-state requires $\nu \delta L-\rho>0$ implying $g_{A}>0$ and $Q>0$ because $\varepsilon<1$.

Examination of Proposition 2 shows that the results we get are very simple. Basically, the dynamic properties of the model are close to that of a basic R\&D-based model, except that our framework is characterized by an expanding variety of pieces of knowledge and not of products (see e.g. Grossman and Helpman, 1991b, ch. 3 and Barro and Sala-iMartin, 1995, ch. 6). Thus, we refrain from conducting comparative statics because it would not add any new insight.

However, the kind of equilibrium depicted here is very different. Beyond the fact that we do not specify any intermediate goods production sector embedding new knowledge, which not only fits with the case of new technologies but also has the appealing property to simplify the analysis, the kind of equilibrium we have characterized displays complete markets. From a technical point of view, we can indeed argue that the basic $\mathrm{R} \& \mathrm{D}$ literature does not solve the non-convexity problem raised by the non-rival property of knowledge through the introduction of imperfect competition (monopoly on the sale of intermediates embedding knowledge), but through an implicit incomplete market assumption: pieces of knowledge are not directly priced.

We can get a more intuitive interpretation of this feature if we examine the expression giving the price of a piece of knowledge at each moment, $v_{t}$. This expression is repeated below for convenience (see Proposition 2):

$$
v_{t}=\frac{\left(\nu L^{X}+L^{A}\right)}{A_{t}}
$$

Similarly to what we mentioned, we can interpret $\nu L^{X} / A_{t}$ and $L^{A} / A_{t}$ as the aggregate willingness to pay at date $t$ to use a piece of knowledge at $t$ for the production of differentiated goods and knowledge, respectively. The interesting point about the instantaneous value of a piece of knowledge given by (11) is that it differs from the expression generally obtained in the standard literature on growth (see e.g. Jones and Williams, 2000). As 
noted by Grimaud and Tournemaine (2006), the equilibrium value of a piece of knowledge considered in standard growth models consists in a fraction of the first term, $\nu L^{X} / A_{t}$, which comes from the monopoly profits on intermediate goods. The second term, $L^{A} / A_{t}$, does not appear because of the incomplete market assumption: researchers do not take into account that the knowledge they produce can be used to make new pieces of knowledge (intertemporal spill-over effect): this is because knowledge is free of charge. This implicit assumption of incompleteness results from the formalization of how intellectual property law worked prior to the recent evolution that followed the emergence of new technologies. However, as argued in Introduction and in Section 2, such formalization is at odds with the recent practices in the new technology sectors. As mentioned, since knowledge is directly patented, both researchers and producers of homogenous goods must pay the right to use the pieces of knowledge. This feature is clearly taken into account in equation (11). Therefore, in the present framework, researchers take into account that the knowledge they produce can be used to make new knowledge. Furthermore, since the micro-markets of knowledge are competitive, and there is no problem of verification and/or exclusion, each piece of knowledge is funded at its optimal level, i.e. the sum of the Lindahl prices. To summarize, we have:

Proposition 3 : Under the assumption that there are micro-markets for knowledge, that these markets are perfectly competitive and that there is perfect verification and exclusion:

a) knowledge does not cause any external effect;

b) knowledge is optimally funded.

This proposition has an important implication. It establishes that in formalizing the evolution of intellectual property law regarding the knowledge produced in new technology sectors, the model displays only one distortion: Cournot competition on differentiated goods markets. The departure from the competitive market structure is necessary to fund research and sustain long term economic growth. That is, it allows firms to fund the payment of knowledge, despite the standard assumption of constant returns to scale with respect to labor (the only private input here) in technologies (1) and (2).

Let us illustrate this argument with an example. Let us assume that the objective of a policy-maker is to increase competition on differentiated goods markets. From Proposition 2 , the price of differentiated goods, $p_{t}$, is higher than the marginal cost of production given by $1 /\left(\gamma\left(A_{t}\right)^{\nu}\right)$. We have: $p_{t}=m /\left(\gamma\left(A_{t}\right)^{\nu}\right)$ with $m=L / L^{X}>1$. Interestingly, the term $L / L^{X}$ represents an indicator of the degree of competition on the markets of differentiated goods: as $L / L^{X}$ approaches one, markets are more competitive. Thus, to achieve her goal, the policy-maker can for example introduce a subsidy-policy on the quantity of labor, 
$L^{X}$. To avoid other distortionary effects, the policy-maker collects lump-sum taxes from individuals and has a balanced budget at any moment. When the subsidy is introduced, $L^{X}$ increases. It results a reduction of the price of differentiated goods, $p_{t}$, and an increase of the number of firms in each sector, $Q$ (see equation (23) given in Appendix). Ceteris paribus there is a dilution of profits realized on differentiated goods. Since firms have less funds to buy knowledge, they reduce the quantity of resources they allocate to make research. This effect is captured in a simple way by the model. Firms reallocate labor one for one between the production of differentiated goods and research. This is because we have $L=L^{X}+L^{A}$ at each moment. As a consequence, the level of growth is lower. To summarize, we can state:

Proposition 4 : More competition on differentiated goods markets leads to a dilution of economic profits, then to a reduction of investments in R\&D and a lower level of growth.

Before closing this Section, we must mention that in the particular model developed in this paper, the dynamic general equilibrium with Cournot competition and free entry leads to an optimal allocation of labor across the differentiated goods production sector and the research activity. The same type of result had been obtained by Barro and Sala-i-Martin (1995, ch. 6, Section 2) in a model with an expanding variety of consumer products. In the present paper, three reasons explain this particular result. First, the Cournot competition leads to a price for differentiated goods which is non-optimal (it is above the marginal cost of production). However, because of the property of symmetry, the relative prices of goods themselves are not affected by imperfect competition. Second, as labor supply is inelastic, it is unresponsive to wage changes. Third, knowledge is optimally funded. In the next sub-section, we will see that the equilibrium is no longer optimal when knowledge is not funded optimally.

\subsection{Introducing verification and exclusion problems}

In this sub-section, we attempt to formalize in a simple way the problems of verification and exclusion encountered by sellers of pieces of knowledge. It should be mentioned that intellectual property institutions, chiefly patent offices, attempt to solve some of these problems. They try to check that a new piece of knowledge seeking protection is indeed different from the state of the art and previous patents, comes from an inventive activity and can have an industrial application. When a researcher wants to obtain a patent she must give all the references she has used to produce the new piece of knowledge. Legal firms which buy and/or manage patents without performing R\&D themselves also exist in 
the US. These firms aim at spotting who uses a protected invention. If they find someone, they try to negotiate royalties. Of course, in any case, if the bargain does not yield any result, the judiciary system can force someone to pay.

The main point here is that the producer of a new piece of knowledge can have difficulties to prevent illegal uses of her product, because of piracy for example. To model this situation, we assume that the instantaneous payment perceived by firm $q_{j}$ is given by

$$
\widehat{v_{q_{j}}}=\eta v_{q_{j}},
$$

where $0<\eta \leq 1$ represents the constant and exogenous share of the willingness to pay to use a piece of knowledge at $t$ that is extracted. A higher value of $\eta$ means that the problems of verification and exclusion are weaker. Taking into account (12), we examine how the symmetric equilibrium is modified. Noting that the instantaneous price of a piece of knowledge is now given by $\widehat{v_{t}}=\eta\left(\nu L^{X}+L^{A}\right) / A_{t}$, we get the following growth rate of consumption and number of firms in each sector:

$$
\begin{gathered}
g_{c}=\frac{\eta \delta \nu L-\rho}{\theta+(1-\nu)(1-\eta) / \nu}, \\
Q=\frac{\delta L(1-\varepsilon)[\theta \nu+(1-\nu)(1-\eta)]}{\eta \delta \nu L-\rho} .
\end{gathered}
$$

Examination of the two previous equations leads to:

Proposition 5 : With verification and exclusion problems:

a) long-run growth is lower: $\partial g_{c} / \partial \eta>0$;

b) the number of firms in each sector $j$ is higher: $\partial Q / \partial \eta<0$.

The results of this proposition have an intuitive interpretation. An increase of $\eta$ means that researchers can appropriate a greater amount of willingness to pay. On the one hand, investments in research become more profitable. Thus, firms allocate more labor to research activities. This induces an increase of the arrival rate of pieces of knowledge, and in turn of the economic growth rate. On the other hand, when $\eta$ increases, this means that firms need more resources in order to pay for knowledge which has a negative effect on their number in each sector.

The above results are important because the question of over or under-investments in research is crucial regarding long-run growth. Usually, R\&D-based models predict that we can obtain either an excessive or an insufficient allocation of resources in research leading to an insufficient or excessive growth. This well-known result in the vertical differentiation class of models (e.g. Grossman and Helpman, 1991a; Aghion and Howitt, 
1992) has also been obtained by Benassy (1998) in a model "à la Romer (1990)". On the empirical side, the data show unambiguously that research spending are insufficient. For instance, Jones and Williams (1998) estimate that actual investments are at least four times below what would be socially optimal. It is generally argued that this feature is due to some distortions: the monopolistic behavior of the producers of goods embedding knowledge, the intertemporal spill-over effect of knowledge or the creative-destruction effect. Interestingly, our setting allows us to give an alternative explanation in the case of new technologies. Here, insufficient research spendings come from the public good nature of knowledge itself and, in contrast with the standard literature, are explained in a complete market perspective. Basically, researchers cannot appropriate the entire amount of the surplus they create because they face problems of verification and exclusion, an explanation which fits nicely with the real world observations in the case of new technologies.

\section{Conclusion}

An evolution of intellectual property rights has taken place over the last decades following the rise of importance in the new technology sectors: pieces of knowledge in the software industry or biotechnology sector are now directly protected by patents. The crux of the problem is that there is a growing discrepancy between the theoretical treatment of knowledge in growth models and the real-world evolutions.

In this paper, we have tried to account for these evolutions. We have presented a simple growth model in which knowledge is directly patented. To deal with the problem of non-convexity of technologies in which knowledge is an input, we have assumed that, on the markets for private differentiated goods, firms compete à la Cournot and earn strictly positive profits which are used to buy knowledge. Moreover, we have assumed that pieces of knowledge, which are perfectly substitutes, are exchanged on micro-markets which work as perfect competitive ones. We have shown a simple way to account for the verification and exclusion problems that go along with the public (i.e. non-rival or non-depletable) good property of knowledge.

Beyond the question raised in this article, we think that the methodology presented here has one more interest. From a technical point of view, the model is very simple because there are no intermediate private goods embedding knowledge. Moreover, it has the interesting property to display only one market distortion (Cournot competition). Since such distortion can easily be identified and removed, we can argue that our framework is suitable to study more complex issues such as sustainable development, credit funding, 
unemployment, and others. To illustrate this argument, we can refer to Grimaud and Rouge (2008). They develop a similar model to ours to study environmental issues. As argued by the authors, the analysis of the effects of the pollution externality is greatly facilitated because it does not interact with other external effects inherent to standard R\&D-based models.

\section{Appendix}

\subsection{Problem of firm $q_{j}$}

From the Hamiltonian of the firm's problem we get the following first order conditions:

$$
\begin{gathered}
\frac{\partial H_{t}}{\partial X_{q_{j} t}}=\left(L E_{t}\right)^{1-\varepsilon}\left(X_{j t}\right)^{\varepsilon-1}-\left(A_{t}^{q_{j}}\right)^{-\nu} / \gamma+(\varepsilon-1) X_{q_{j} t}\left[\left(L E_{t}\right)^{1-\varepsilon}\left(X_{j t}\right)^{\varepsilon-2}\right]=0 \\
\frac{\partial H_{t}}{\partial L_{q_{j} t}^{A}}=e^{-\int_{0}^{t} r_{u} d u}-\xi_{t} \delta A_{t}^{q_{j}}=0 \\
\frac{\partial H_{t}}{\partial A_{t}^{q_{j}}}=e^{-\int_{0}^{t} r_{u} d u}\left[\nu X_{q_{j} t}\left(A_{t}^{q_{j}}\right)^{-\nu-1} / \gamma-v_{q_{j} t}\right]+\xi_{t} \delta L_{q_{j} t}^{A}=0 \\
\frac{\partial H_{t}}{\partial A_{q_{j} t}}=v_{t} e^{-\int_{0}^{t} r_{u} d u}=-\dot{\xi}_{t} .
\end{gathered}
$$

Simple manipulation of (15) yields equation (8). Integrating (18) between $t$ and infinity gives $\int_{t}^{\infty}-\dot{\xi}_{s} d s=\int_{t}^{\infty} v_{s} e^{-\int_{0}^{s} r_{u} d u} d s$, that yields $\xi_{t}-\xi_{\infty}=\left(e^{-\int_{0}^{t} r_{u} d u}\right) \int_{t}^{\infty} v_{s} e^{-\int_{t}^{s} r_{u} d u} d s$. Using the transversality condition and $A_{q_{j} t}>0$ for all $t$, we have $\xi_{\infty}=0$. Thus, using $V_{t}=\int_{t}^{\infty} v_{s} e^{-\int_{t}^{s} r_{u} d u} d s$, we get $\xi_{t}=\left(e^{-\int_{0}^{t} r_{u} d u}\right) V_{t}$. Plugging this result in (16), yields equation (9). Similarly, (17) becomes $\nu X_{q_{j} t}\left(A_{t}^{q_{j}}\right)^{-\nu-1} / \gamma-v_{q_{j} t}+V_{t} \delta L_{q_{j} t}^{A}=0$. Eliminating $V_{t}$ between this equation and (9) gives $v_{q_{j} t}=\nu X_{q_{j} t}\left(A_{t}^{q_{j}}\right)^{-\nu-1} / \gamma+L_{q_{j} t}^{A} / A_{t}^{q_{j}}$. Using (1), we get equation (10).

\subsection{Proof of Proposition 1}

We proceed in two steps. First, we compute the main conditions that emerge at date $t$ on each market. Second, we characterize the steady-state equilibrium.

1) Markets conditions for a symmetric equilibrium

From Proposition 1, each firm uses the whole stock of knowledge: $A_{t}^{q_{j}}=A_{t}$ for all $q_{j}$. Thus, we replace $A_{t}^{q_{j}}$ by $A_{t}$ in all equilibrium conditions. On differentiated goods markets there 
is Cournot competition and free entry in each sector $j$. Using (8), we get the equilibrium quantity of each differentiated good which is produced in each sector:

$$
X_{t}=L E_{t}\left\{\gamma\left(A_{t}\right)^{\nu}\left[1+\frac{(\varepsilon-1)}{Q}\right]\right\}^{1 /(1-\varepsilon)} .
$$

Using (1) we get the aggregate production function of each differentiated good:

$$
X_{t}=\frac{\gamma\left(A_{t}\right)^{\nu} L^{X}}{N}
$$

Equation (6) yields the Cournot equilibrium price of differentiated good $j$ :

$$
p_{t}=\left\{\gamma\left(A_{t}\right)^{\nu}\left[1+\frac{(\varepsilon-1)}{Q}\right]\right\}^{-1} .
$$

Note that for $Q=1$ (monopoly case), we get the standard result $p_{t}=1 /\left(\varepsilon \gamma\left(A_{t}\right)^{\nu}\right)$, where $1 /\left(\gamma\left(A_{t}\right)^{\nu}\right)$ is the marginal cost and $1 / \varepsilon>1$ represents the mark-up.

The free entry condition on the markets of differentiated goods implies $\pi_{q_{j} 0}=0$. Using equations (20) and (21), this condition becomes

$$
\pi_{q_{j} 0}=\int_{0}^{\infty}\left[\{[1+(\varepsilon-1) / Q]\}^{-1} L^{X} / N Q-L / N Q\right] e^{-\int_{0}^{t} r_{u} d u} d t=0 .
$$

Note that with a sunk or fixed cost of entry and exit equal to zero, the spot profit of the firms must be zero at all times. Simplifying, we thus have

$$
\left[1+\frac{(\varepsilon-1)}{Q}\right]^{-1} L^{X}-L=0 .
$$

From (10), we get the price received for each piece of knowledge:

$$
v_{t}=\sum_{j=1}^{N} \sum_{q_{j}=1}^{Q_{j}} v_{q_{j} t}=\frac{\left(\nu L^{X}+L^{A}\right)}{A_{t}} .
$$

From (9), the value of a piece of knowledge at $t$ is

$$
V_{t}=\frac{1}{\delta A_{t}}
$$

From (2), the law of motion of the total stock of knowledge is given by

$$
\dot{A}_{t}=\delta L^{A} A_{t}
$$


From equation (7) and $r=v_{t} / V_{t}+g_{V}$, we have:

$$
\theta g_{c}+\rho+g_{p}=v_{t} / V_{t}+g_{V}
$$

\section{2) Equilibrium solution}

Prices:

The prices and their growth rates follow directly from (21), (24), (25), (27).

Levels of quantities and their growth rates:

Using (24) and (25), we get $v_{t} / V_{t}=\delta \nu L^{X}+\delta L^{A}$. Differentiating (21) and (25) with respect to time yields $g_{p}=-\nu g_{A}$ and $g_{V}=-g_{A}$. The aggregate technology of differentiated goods (20) and the law of motion of knowledge (26) imply $g_{c}=g_{X}=\nu g_{A}$ and $g_{A}=\delta L^{A}$, respectively. Therefore, using the labor constraint (5) with $r=v_{t} / V_{t}+g_{V_{t}}=\theta g_{c}+$ $\rho+g_{p}$ (see equation (27)), we get the quantities of labor devoted to the production of differentiated goods and to research.

Number of firms, $Q$, that composes each sector $j$ :

Since $L^{X}$ has been determined previously, we get the equilibrium value of $Q$ by using (23). 


\section{References}

Aghion, P., and P. Howitt. (1992). "A model of growth through creative destruction," Econometrica 60, 323-351.

Arnold, L. (1998). "Growth, welfare, and Trade in an Integrated Model of HumanCapital Accumulation and Research" Journal of Macroeconomics 1, 84-105.

Arora, A., and A. Fosfuri. (2000). "The Market for Technology in the Chemical Industry: Causes and Consequences," Revue d'Économie Industrielle 92, 317-334.

Arrow, K. J. (1962). "Economic Welfare and the Allocation of Resources for Inventions." In Richard R. Nelson (ed.) The Rate and Direction of Inventive Activity. Princeton: Princeton University Press and NBER.

Barro, R. J., and X. Sala-I-Martin. (1995). Economic Growth. New-York: McGrawHill.

Benassy, J. P. (1998). "Is there too little research in endogenous growth with expanding product variety?," European Economic Review 42, 61-69.

Dasgupta, P., K. G. Mäler, G. B. Navaretti and D. Siniscalco. (1997). "On Institutions that Produce and Disseminate Knowledge." Fondazione Eni Enrico Mattei, Nota di lavoro 68.97.

Feehan, J. P. (1989). "Pareto-efficency with Three Varieties of Public Inputs," Public Finance 2, 237-248.

Gallini, N., and S. Scotchmer. (2003). "Intellectual Property: When is it the Best Incentive System?" In Adam Jaffe, Joshua Lerner and Scott Stern (eds), Innovation Policy and the Economy, vol. 2, 51-78. Cambridge: MIT Press. Also forthcoming in Fabrizio Cafaggi, Antonio Nicita and Ugo Pagano (eds.), Legal Orderings and Economic Institutions. Routledge Studies in Political Economy.

Grimaud, A., and L. Rouge. (2004). "Polluting Non Renewable Resources, Tradeable Permits and Endogenous Growth," International Journal of Global Environmental Issues $4,38-57$.

Grimaud, A. and L. Rouge. (2008). "Environment, Directed Technical Change and Economic Policy," Environmental and Resource Economics, forthcoming.

Grimaud, A., and F. Tournemaine. (2006). "Social Value of Innovations, Distortions and R\&D Investments: First Best versus Second Best Equilibria in Growth Models," Revue d'Economie Politique 116, 7-22.

Grimaud, A., and F. Tournemaine. (2007). "Why can an environmental policy tax promote growth through the channel of education?" Ecological Economics 62, 27-36. 
Grossman, G. M., and E. Helpman. (1991a). "Quality ladders in the theory of growth," Review of economic studies 58, 557-586.

Grossman, G. M., and E. Helpman. (1991b). Innovation and Growth in the Global Economy. MIT Press, Cambridge.

Howitt, P. (1999). "Steady Endogenous Growth with Population and R\&D inputs Growing", Journal of Political Economy 107, 715-730.

Jones, C. I. (1995). "R\&D-Based Models of Economic Growth," Journal of Political Economy 105, 759-784.

Jones, C. I. (2002). "Source of U.S. Economic Growth in a World of Ideas", American Economic Review 92, 220-239.

Jones, C. I. (2003). "Population and Ideas: A Theory of Endogenous Growth." In Philippe Aghion, Roman Frydman, Joseph Stiglitz, and Michael Woodford (eds), Knowledge, Information, and Expectations in Modern Macroeconomics, in Honor of Edmund S. Phelps. Princeton: Princeton University Press.

Jones, C. I., and J. C. Williams. (1998). "Measuring the Social Return to R\&D," Quaterly Journal of Economics 113, 1119-1135.

Jones, C. I., and J. C. Williams. (2000). "Too Much of a Good Thing? The Economics of Investment in R\&D", Journal of Economic Growth 5, 65-85.

Kaizuka, K. (1965). "Public Goods and Decentralization of Production," Review of Economics and Statistics 47, 118-120.

Manning, R., J. R. Markusen, and J. Mc Millan. (1985). "Paying for Public Inputs," American Economic Review 75, 235-238.

Mas-Colell, A., M. D. Whinston, and J.R. Green. (1995). Microeconomic Theory. Oxford: Oxford University Press.

Peretto, P. (1996). "Sunk Costs, Market Structure, and Growth," International Economic Review 37, 895-923.

Peretto, P. (1998). "Technological Change and Population Growth," Journal of Economic Growth 3, 283-311.

Peretto, P. (1999). "Cost Reduction, Entry, and the Interdependence of Market Sructure and Economic Growth," Journal of Monetary Economics 43, 173-195.

Quah, D.T. (1997). "Increasingly Weightless Economy," Bank of England Quarterly Bulletin 37, 27-59.

Quah, D.T. (2001). "The Weightless Economy in Economic Development". In Matti Pohjola (ed.), Information Technology, Productivity and Economic Growth: International Evidence. Oxford: Oxford University Press.

Romer, P. (1990). "Endogenous Technological Change," Journal of Political Economy 
98, S71-S102.

Sandmo, A. (1972). "Optimality Rules for the Provision of Collective Factors of Production," Journal of Public Economics 1, 149-157.

Scotchmer, S. (1991). "Standing on the Schoulders of Giants: Cumulative Research and the Patent Law," Journal of Economic Perspective 5, 29-41.

Scotchmer, S. (1999). "Cumulative Innovations in Theory and Practice," Working paper, U.C. Berkeley.

Scotchmer, S. (2005). Innovation and Incentives. Cambridge: MIT Press.

Smulders, S., and T. van de Klundert. (1995). "Imperfect Competition, Concentration and Growth with Firm-Specific R\&D," European Economic Review 39, 139-160.

Smulders, S., and T. van de Klundert. (1997). "Growth, Competition and Welfare," Scandinavian Journal of Economics 99, 99-118. 